\title{
LAKE BIWA
}

Lake Biwa, edited by S. Horie. Dr. W. Junk Publishers, Kluwer Academic Publishers Group, Dordrecht, 1984, 654 pp., cloth, U.S. $\$ 145.00 / £ 88.95$, ISBN: 90-6193-095-2.

True interest in Lake Biwa focuses upon its age rather than its large size, the largest of the lakes of Japan. Although Biwa has experienced numerous complex alterations in water level over the past half million years, the basin has maintained sufficient volume to permit refuges for both freshwater and marine relict species of plants and animals. The complexities of past crustal movements and climatic variations obscure changes in the tectonic basin, but organismal endemism is widespread, and of great concern for preservation under the pressures of extensive human development in the drainage basin.

The monograph Lake Biwa is an effective review of contemporary understanding of this relict water. Professor Shoji Horie, Director of the Institute of Paleolimnology and Paleoenvironment of Kyoto University on Lake Biwa, coordinated and edited the numerous chapter treatments by specialists. The book is separated into five topical sections following a brief overview on the general features of Lake Biwa.

A detailed evaluation of the geomorphology and geology of the Lake Biwa drainage basin, occupying about a fifth of the book, provides insight into the complex processes and features that characterize the ancient tectonic basin. The numerous faulting systems are nearly all active and lead to heterogeneous landform patterns in the catchment area, which are still under evaluation and interpretation. So many geological and geochemical data have been collected that subsequent evaluations will undoubtedly alter details of this summary. However, the essential sequences are known, as reviewed in appreciable stratigraphic detail. A concluding geotectonic settings chapter summarizes salient features of contemporary interpretations.

The second section on contemporary limnology of Lake Biwa, consisting of over a third of the book, addresses five topics in varying detail: meteorology; physical; chemical; biological limnology; sediment metabolism. The large basin, steep mountainous terrain, and insular location result in complex thermal and wind patterns. These physical conditions provide a spatially variable setting for surficial and internal hydrodynamics. Observed fluctuations in currents and thermal stratification patterns permit application of existing and modified models for seiches, which have numerous analogies to conditions in the Laurentian Great Lakes.

The warm, monomictic character of Lake Biwa, however, permits only a winter circulation period in the main basin and stratification for much of the year. The shallower southern basin is polymictic and is rarely stratified for any appreciable period. As a result the chemical and planktonic constituents vary 
extensively spatially within the basin and seasonally. The inorganic constituents are summarized and a few nutrient budgets are presented. Representative algae, phytoplankton, aquatic macrophytes, zooplankton, and benthos are briefly described with little interpretation.

Well over a third of this large volume is devoted to the paleolimnology of Lake Biwa. Few lakes have been studied in similar detail, and certainly the historical records of no other relict lake have been examined as extensively. In addition to the major $200-\mathrm{m}$ core, numerous other cores have been taken and examined as well for physical, chemical, and biological characteristics and constituents. Sediments have been variously aged and examined for paleomagnetism. Inorganic and organic constituents of the stratigraphic record have been described in extensive detail. Progress has been made in coupling the major historical changes recorded in Lake Biwa sediments to tectonic activities of its basin, major changes in sea level, and global glacial-interglacial cycling.

Two small concluding chapters address the biogeography of endemic and introduced flora and fauna of Lake Biwa, as well as the major influences of human activities upon the lake. Regulation of the lake level and a general small but significant reduction of water level has lessened certain flooding problems, but it has also created new problems, e.g. land reclamation. Contamination and enrichment problems exist but are being addressed with appreciable vigor, commensurate with the national treasure in the biota of this ancient lake.

Professor Horie has provided an immense service in leading effective summaries of the extensive understanding of Lake Biwa. Much of the older literature and records on the lake are unavailable to most limnologists and other scientists because of the language difficulties and often obscure literature sources. Most of the information is presented conservatively, and often I would have welcomed greater interpretation of the descriptive analyses by the experts most familiar with the data and subjects being treated. Numerous typographical errors occur, and the writing is frequently grammatically awkward. However, these problems are minor and detract little from a book that should be in all science libraries.

ROBERT G. WETZEL Department of Biology and Great Lakes Research Division The University of Michigan 